\title{
Historicizando a Transexualidade em Direção a uma Psicologia Comprometida
}

Lara Araújo Roseira Cannone ${ }^{1}$

${ }^{1}$ Universidade Federal da Bahia, BA, Brasil.

Resumo: A despatologização das identidades transexuais e travestis tem sido uma luta árdua e conta com a colaboração de diversos setores, como movimentos sociais e categorias profissionais. Atualmente conquistas consideráveis a esse respeito já podem ser identificadas, entre elas, a retirada da seção dos transtornos mentais na Classificação Internacional de Doenças (CID-11), passando para condições relativas à saúde sexual. Também a Psicologia tem assumido postura participativa a favor da diversidade de gênero, assim como das orientações sexuais. Neste contexto, o presente trabalho se estrutura em modelo de ensaio científico de cunho feminista que discorre sobre as reflexões acima e demais informações atualizadas sobre essa demanda aparente, através do ponto de vista de uma psicóloga que está enquanto coordenadora de um grupo de trabalho a respeito da população LGBT no CRP 3a região-BA e dos atuais debates do Sistema Conselhos na defesa dos Direitos Humanos. A exemplo, ações do Conselho Federal de Psicologia, e seus respectivos regionais engajados nas causas LGBT, vêm se intensificando para repensar paradigmas e enfrentar as disparidades sustentadas pela patologização da população transexual e travesti. Haja vista que se trata de um campo ainda incipiente na profissão, tornase útil visibilizar atuações contemporâneas no sentido de colaborar com o desenvolvimento da temática na Psicologia como ciência e profissão.

Palavras-chave: Psicologia, Transexualidade, Saúde Mental.

\section{Historicizing Transsexuality toward a Committed Psychology}

\begin{abstract}
The depathologization of transsexual and transvestite identities involves a fight against the disease and has had the contributions of several sectors, such as social movements and professional categories. Currently, some considerable achievements in this regard can be identified., among them, a withdrawal from the metadata of Mental Disorders in the International Classification of Diseases (ICD-11), of the conditions related to sexual health. Psychology has also been in favor of gender diversity as well as sexual orientations. In this context, the present work is structured as a feminist scientific demonstration that discusses the above reflections and the latest information on this demand, from the point of view of a Psychologist that coordinates a work group for the respect of the LGBT population in the 3rd CRP in the BA region and the current debates of the Council System in the defense of Human Rights. For example, the actions of the Federal Council of Psychology and its respective regional councils engaged in LGBT causes have intensified to reprehend paradigms and face the inequalities sustained by the pathologization of the transsexual and transvestite population. Since it is a field still incipient in the profession, it becomes useful to visualize contemporary performances to collaborate with the development of this subject in Psychology as science and profession.
\end{abstract}

Keywords: Psychology, Transsexuality, Mental Health. 


\title{
Historizando la Transexualidad Hacia una Psicología Comprometida
}

\begin{abstract}
Resumen: La despatologización de las identidades transexuales y travestis ha sido una lucha ardua y cuenta con la colaboración de varios sectores, como los movimientos sociales y las categorías profesionales. Ya se pueden identificar logros considerables a este respecto, entre ellos, la eliminación de la sección de trastornos mentales en la Clasificación Internacional de Enfermedades (CIE-11), pasando a condiciones relacionadas con la salud sexual. La psicología también ha tomado una postura participativa a favor de la diversidad de género, así como las orientaciones sexuales. En este contexto, el presente trabajo está estructurado en un modelo de ensayo científico feminista que discute las reflexiones anteriores y otra información actualizada sobre esta aparente demanda, desde el punto de vista de una psicóloga que está coordinando un grupo de trabajo sobre población LGBT en el CRP $3^{\circ}$ regiónBA y los debates actuales del Sistema de Consejos en defensa de los Derechos Humanos. Por ejemplo, las acciones del Consejo Federal de Psicología, y sus respectivos grupos regionales involucrados en causas LGBT, se han intensificado para repensar los paradigmas y abordar las disparidades sostenidas por la patologización de la población transgénero y travesti. Teniendo en cuenta que este campo aún es incipiente en la profesión, es útil hacer visibles las acciones contemporáneas para colaborar con el desarrollo del tema en Psicología como ciencia y profesión.
\end{abstract}

Palabras clave: Psicología, Transexualidad, Salud Mental.

\section{Introdução}

A despatologização das identidades transexuais e travestis tem sido uma luta árdua e conta com a colaboração de diversos setores, como movimentos sociais e categorias profissionais. Atualmente conquistas consideráveis a esse respeito já podem ser identificadas, entre elas, a retirada da seção dos transtornos mentais na CID-11, passando para condições relativas à saúde sexual.

A Psicologia tem se posicionado institucionalmente desde 2011 a favor da despatologização, principalmente via Sistema Conselhos (Federal e Regionais). Recentemente incorporou-se mais um marco, e principal regulamento acerca das identidades de gênero, a Resolução no 01/2018 que estabelece normas de atuação para psicólogas/os em relação às pessoas trans (Resolução No 1, 2018).

Todavia, sabe-se que o cenário político e a conjuntura atual do país indicam um árduo caminho a ser percorrido para a superação de estigmas e impedimentos de cidadania que vão além de normativas; é preciso lembrar que o Brasil lidera o ranking internacional em episódios recorrentes de transfobia. A própria Resolução já se apresenta como alvo de tentativas internas à categoria e externas de boicote, além do desconhecimento de sua existência por grande parte de psicólogas e psicólogos.

Os saberes psi (Psiquiatria, Psicanálise e Psicologia) são pioneiros em adentrar a discussão de sexualidade e gênero, mas não os primeiros a desconstruí-la. $\mathrm{O}$ desafio se estende aos dias atuais, o que pode ser notado através do diálogo frágil com os estudos de gênero, feministas e queer.

Esta é uma temática historicamente de disputa dos campos da moral, religião, âmbito jurídico, discursos científicos, mídia etc. Se instaurando o clássico tripé discursivo do Direito, da Medicina e da Religião, basicamente por meio da ideia de punição, tratamento e pecado. Com isso, percebe-se que ficam omissos dos registros históricos oficiais o protagonismo de narrativa, lugar de fala e representatividade das pessoas lésbicas, gays, bissexuais, travestis, transexuais e transgêneros (LGBT).

Assim como nas demais esferas macrossociais, esse efeito recai na Psicologia hegemônica de maneira que se estabeleceu a ideia de corpos desviantes com associação à loucura, delinquência, com direcionamento ao tratamento ou encarceramento. Um exemplo ilustrativo dessa ocasião é o período higienista brasileiro, o qual internava compulsoriamente pessoas dissidentes da norma: prostitutas, dependen- 
tes químicos, LGBT. O que parece ser uma memória antiga, na verdade acompanha a recente história da Psicologia Brasileira que completa 57 anos.

Deste modo, fica nítida a construção de modelos legítimos de existência; o que exige o estabelecimento do contraste entre normal e patológico. Assim sendo, vê-se as identidades de gênero e orientações sexuais serem alvo desse processo incessante, ganhando terminologias variadas: histeria, perversões sexuais, homossexualismo, lesbianismo, transexualismo... por que será que não se ouve falar em heterossexualismo?

O ser humano é um ser de linguagem, logo, a forma que a comunicação se dá é efeito da nossa cultura e também age na constituição subjetiva. Importa pensar na disseminação do termo trans, enquanto o cis é desconhecido. Ou, que o termo cis surge 70 anos depois do termo trans, assim como o termo heterossexual surge depois do homossexual.

Então nesse trânsito entre perversão, transtorno, disforia e psicose, pouco se considera a diversidade da existência humana e o caráter político e complexo dos corpos. O que pode recair na tutela, tentativa de controle e patologização desses corpos. Por essa via, cabe à Psicologia se revisitar já que mesmo não criando normatização pela biologia, corre o risco de normatizar pela ideia de essência.

$\mathrm{Na}$ atuação, é preciso considerar o sujeito em sua integralidade e os aspectos relacionais com o outro. Enquanto se prioriza apenas a orientação sexual ou identidade de gênero, aspectos caros são negligenciados como a história de vida, raça/etnia, classe social, faixa etária. Ademais, o critério de análise da saúde ou sofrimento mental vem exclusivamente do gênero/sexualidade ou com a repercussão do contexto, das regras sociais, dos sistemas de opressão sobre essas nuances?

Sabe-se que as violências não se resumem ao setor da saúde mental, mas certamente interagem direta ou indiretamente. Pessoas trans são expulsas da vida em sociedade, empurradas para guetos através de um processo de segregação desde o núcleo familiar, escolar, laboral e afetivo. Representam um grupo de vulnerabilidade em termos de escolaridade baixa, ideação suicida, trabalhos desvalorizados, ascensão social, dificuldade em encontrar parceiros(as) sexuais e relacionamentos, impedimentos aos serviços de saúde, habitação de qualidade e alto risco de sofrer agressões.
Percebe-se que questões de necessidades básicas pertencem a esse debate. Se pessoas trans não possuem acesso digno ao mercado de trabalho, à saúde, à segurança, ao afeto, ou mesmo usar um banheiro sem constrangimento, não se pode ignorar a incidência desses fatores na saúde mental para um exercício profissional ético.

Dito isto, gênero e sexualidade têm certamente pontos em comum. São ambos políticos e envolvem relações de poder, inferiorização de uns em detrimento do privilégio de outros. São campos de luta, consensos, disputas e resistência. São esferas complexas, plurais, que demandam estudos comprometidos com a transformação social.

Um caminho é através do questionamento da objetividade e neutralidade da ciência convencional, pondo em xeque o limite de território entre os valores manifestos na moralidade social e no aparato cognitivo. Adotar o posicionamento de que a ciência não está isenta de valores permite analisar como isto reflete no percurso histórico do conceito da transexualidade, por meio de uma leitura crítica e disposta a apresentar também os progressos.

\section{Método}

No sentido de expor o trajeto histórico da definição de transexualidade e do entendimento acerca de identidades de gênero, o presente texto segue o formato de ensaio teórico cunhado na epistemologia feminista.

A linha do tempo se inicia no século XIX, a partir do destaque da época colocado nas orientações sexuais, sobretudo na expressão da homossexualidade como objeto de investigação científica. Em seguida são apresentadas pesquisas popularizadas na década de 1950 por médicos nos EUA com casos de intersexualidade e transexualidade em hospitais com alas psiquiátricas, como o Hospital John Hopkins.

Prossegue-se até a incorporação política de movimentos sociais e outras narrativas de ciência principalmente a partir da década de 1970 até os dias atuais, foram delimitados entre eles o movimento feminista, o LGBT, queer e transfeminismos. O cerne do estudo está em relacionar esse percurso com a atuação da Psicologia, refletindo sobre a questão da saúde mental dos sujeitos trans nesse processo.

Situando brevemente o que pretende a epistemologia feminista, baseada nas contribuições de Harding (2004), não é possível falar de ciência sem 
admitir que todo conhecimento produzido fala de um lugar parcial. Ou seja, a defesa da ciência acrítica, universal e neutra obedece a um segmento privilegiado da população, o que também silencia vozes marginalizadas. Neste sentido, cabe evidenciar que o lugar de fala da autora do texto também representa uma perspectiva parcial e situada assim como qualquer discurso.

Outro ponto relevante de comentar é que os interesses feministas na ciência não se restringem apenas às causas das mulheres, mas tudo que envolve o campo do saber. Por isso, requer debates integrados entre o cunho científico, político e intelectual.

Propõe um deslocamento do olhar de mundo, afinal, o que se construiu sobre a vida dos grupos historicamente subalternos também fala sobre os grupos privilegiados. À luz de Harding, é possível compreender a diferença de narrativa de mundo ocupada pelo discurso através da posição na malha das relações de poder. Sendo assim, não se trata de um juízo de valor hierárquico, mas de uma aproximação comprometida com o que se produz desvencilhada da ideia de axiomas científicos.

Rumo a esta direção epistemológica, a escolha das/os intelectuais que serão trabalhadas/os no corpo textual, assim como os órgãos profissionais e movimentos políticos abordados circulam entre o campo de conhecimento e produções em gênero e sexualidades. Algumas por conta do pioneirismo, outras por representarem as pautas seja em um nível nacional, seja em nível internacional.

Além disso, a análise contida neste ensaio teórico segue uma linha articulada principalmente com a perspectiva pós-estruturalista que reúne autoras/ es épicas a partir dos conceitos centrais de cisnormatividade, heteronormatividade, corpos dissidentes, estudos queer, performatividades, transfeminismos, entre outros.

Tendo em vista que ainda se tratam de narrativas pouco abordadas na ciência e pela Psicologia hegemônicas, parte-se do uso teórico de categorias fundamentais para as questões ético-políticas que têm convocado incisivamente a categoria, como discurso, relações de poder e instituições sociais.

\section{Resultados e discussão: disputas epistemológicas em questão}

A ciência começa a desenvolver produções específicas sobre pessoas trans a partir de meados do século $\mathrm{XX}$ e as referências para o assunto, por muito tempo, se restringiram aos saberes médicos e psi.

Aliados à lógica da patologia, não dialogavam com perspectivas plurais e críticas, como as que surgiriam algumas décadas depois, a exemplo dos estudos queer-traduzidos por Bento (2014) como estudos transviados. Atualmente, o conhecimento produzido acerca de gênero e sexualidades prossegue sendo uma área de intensa disputa.

Ao longo da história, praticamente tudo que se conhece formalmente sobre a população trans é produto do conhecimento médico, jurídico e moral. Em um primeiro momento, ainda no século XIX, não se fazia distinção entre identidade de gênero e sexualidades, as diferentes expressões eram resumidas à homossexualidade que, por sua vez, funcionava como um termo guarda-chuva para todas as pessoas LGBT.

Associados (as) à loucura e delinquência, frequentemente eram direcionados (as) ao tratamento ou encarceramento, sendo incisivamente vetado o protagonismo do próprio corpo. Um exemplo ilustrativo dessa ocasião é o período higienista brasileiro, o qual a internação compulsória era o destino de pessoas tidas enquanto dissidentes da norma: prostitutas, dependentes químicos, pessoas em situação de rua, mulheres subversivas e os LGBT.

Diversos foram os encaminhamentos para homossexuais na história: sodomia como pecado; crime institucionalizado; morte legitimada em fogueiras, torturas, pena de morte; exclusão do convívio social; doença, tratamento médico, eletrochoque (Nascimento, 2010).

A cultura homoerótica, como coloca o psicólogo Márcio Nascimento (2010), constitui a humanidade desde épocas não datadas e permeou a cultura ocidental enfaticamente em períodos específicos, como na Grécia Antiga e expressões artísticas do século XIX até agora. Na Grécia, o costume da pederastia era consentido coletivamente; nela, um homem já inserido na esfera pública iniciava um rapaz jovem na cidadania como um rito de passagem, o que hoje poderia ser lido de forma totalmente diferente.

Este breve fragmento do artigo de Nascimento insere questões importantes para se pensar a sexualidade e gênero. Primeiro, evidencia a parte cultural dos acordos em sociedade; um outro aspecto é a mutabilidade ao decorrer do tempo dos costumes, dos tabus, das formas de se relacionar. Ou seja, a maneira que se concebe o gênero e a sexualidade varia na história, 
na cultura, na sociedade, nas relações, nos interesses políticos e morais. Uma evidência disso está na própria variação da linguagem em voga.

Só em 1869, nas terras alemãs, homossexual começa a ser uma palavra utilizada; em 1887 começa a ser empregada em estudos psicopatológicos das sexualidades. Já o termo heterossexual será criado em solo estadunidense 33 anos depois, em 1892.

Difundidas essas categorias, no século XX se instaura a ideia da sexualidade normal, esperada e condizente com a conduta correta; na contramão, se coloca a homossexualidade como condição desvirtuada, pecaminosa e repulsiva. Esse modelo se baseia em três fontes discursivas: machismo, heterocentrismo e heteronormatividade (Nascimento, 2010).

É preciso rememorar que, até 1973, a homossexualidade fazia parte do Manual Diagnóstico e Estatístico de Transtornos Mentais (DSM) enquanto homossexualismo. Termo que prosseguiu sendo utilizado, inclusive equivocadamente por muitos até os dias atuais, só teve sua retirada total na década de 1990 pela Organização Mundial da Saúde (OMS).

Os psicólogos Diogo Sousa e Céu Cavalcanti (2016) consideram outro marco o reconhecimento do Conselho Federal de Medicina (CFM), em 1985, da homossexualidade como expressão humana que não indica doença.

Continuando no curso dos termos forjados, a definição de homofobia surgiu apenas em 1971, mesmo sendo uma prática secular. A homofobia, que também serviu como termo guarda-chuva para as LGBTfobias, é complexa e envolve aspectos a mais que a violência pelo ódio à orientação sexual, se alinha a raça, classe, geração, gênero, regionalismo, estética corporal etc.

Os momentos históricos citados acima mostram um avanço em relação às orientações sexuais, ao mesmo tempo que acompanha, paradoxalmente, em período próximo a categoria de transtorno de identidade de gênero (TIG), posteriormente disforia de gênero, nos códigos de doenças e manuais de transtornos mentais.

A nomenclatura transexual começa a ser empregada nos anos 1920, enquanto cisgênero surge com o atraso de setenta anos desde essa data, em 1990 (Rodovalho, 2017). Um fato contraditório é que as terminologias precursoras do escopo da sexualidade e gênero vêm da área da saúde, por profissionais psi com teor patológico (Sousa, \& Cavalcanti, 2016), e só posteriormente são ressignificadas e aprimora- das pelas ciências sociais que reclamavam um olhar desassociado do estigma da anormalidade.

A transexualidade começa a ser conceituada por Harry Benjamin, médico britânico, em 1953 na perspectiva da psicopatologia. Contemporâneo a essas investigações estão os estudos do médico estadunidense John Money, inspirados em Benjamin. A ciência se debruça nas definições em 1969 e o atestado de disforia vem em 1977 através da Harry Benjamin International Gender Dysphoria Association. Benjamin, assim como os congressos e associações filiados, contribuíram para os tratamentos e inserção nos manuais psiquiátricos (Mattos, \& Cidade, 2016).

As autoras ainda atentam que é "importante mencionar que esse diagnóstico foi, inicialmente, produzido a partir de um estudo clínico efetivado por Harry Benjamin com dez sujeitos transexuais, um número bastante reduzido" (Mattos, \& Cidade, p. 138, 2016).

Ainda no campo psi, frequentemente cita-se o psiquiatra e psicanalista estadunidense, Robert Stoller, autor do notável livro publicado em 1968, Sex and Gender: The Development of Masculinity and Femininity. Esta obra começa a se desenvolver indícios do que se entende por identidade de gênero; seguindo esta linha, o gênero seria separado do sexo por ser constituído pela cultura e psiquismo (Stoller, 1968).

Stoller (1968) contribuiu com discussão pioneira dessas esferas a partir da sua prática clínica, introduzindo o termo identidade de gênero como o atributo pessoal da identificação, do sentimento de ser homem ou mulher superando o biológico.

Mesmo evitando um olhar anacrônico, algumas críticas podem ser feitas às ideias de Robert Stoller por conta do teor de nivelamento de comportamentos masculinos ou femininos, a visão de defeito nas variações das performances e a responsabilização da família na formação da identidade de gênero. Portanto, nota-se o controle pela normalidade binária da experiência de gênero e a diferenciação dos papéis sexuais com base heteronomativa. Os casos clínicos eram trabalhados como identidades de gênero desviantes.

Esse e outros estudos similares da época utilizavam homens como referência para explicar os fenômenos, justificando serem a maioria das desordens pelos efeitos das grandes exigências proferidas pela masculinidade. Conceitos psicanalíticos eram populares nas explicações, com foco na dinâmica edípica dizia-se que o homem gay teria passado por uma falha 
na substituição da identificação com a mãe para o pai, e então segue o mesmo objeto de amor materno, os homens (Stoller, 1968).

Para a transexualidade, os rumos teóricos eram parecidos. Definia-se como resultado da ligação intensa com a mãe ao ponto dos indivíduos se verem também enquanto mulheres; até então, homens transexuais não agregavam os estudos gerais. Em termos amplos, a linha de pensamento seguida era a partir da identificação psicológica com o outro.

Ann Oakley, renomada socióloga feminista, é mais uma referência pioneira nos estudos sobre sexo e gênero. Em artigo de 1972, ela recorre aos estudos antropológicos que mostram como as definições de gênero variam nas culturas, apesar da constante sexo ser usada como referência. E, apesar de a cultura estar convencida da legitimidade dessas normas, jamais vão convergir totalmente quando comparada a norma de uma outra cultura: "não há duas culturas sequer que concordariam completamente no que distingue um gênero do outro" (Oakley, 2016, p. 65).

Até a década de 1990, utilizava-se o termo transexualismo e, com a diferenciação da transexualidade da esfera das orientações sexuais, alterações diagnósticas surgiram. O Código Internacional de Doenças incluiu, em sua décima versão (CID-10), a transexualidade na categoria de Transtorno de Identidade Sexual; enquanto o DSM-IV incluiu em TIG. No entanto, é preciso salientar que as causas e origens que justificariam a patologia na transgeneridade nunca foram constatadas.

É manifesto que esses acontecimentos propiciam um campo de tensão constante entre profissionais, pacientes e militantes. As psicólogas Sampaio e Coelho (2013) exemplificam, através das atualizações frequentes de ambos os manuais acima (atualmente nas suas versões, respectivamente, $11^{\mathrm{a}}$ e $5^{\mathrm{a}}$ ), o indicador da convenção do que é doença não se tratar de um axioma, pois se localiza e se reinventa no período histórico ao qual se refere.

À medida que os estudos sobre a transexualidade foram crescendo, no século $\mathrm{XX}$, os saberes psis os acompanharam em prol de "construir protocolos e produzir diagnósticos diferenciais da transexualidade em relação às homossexualidades" (Bento, 2014, p. 49). A autora denomina esse veículo como dispositivo da transexualidade, que coloca o fenômeno em linguagem científica imersa em definições parciais e contaminadas de valores, porém sem essa confissão explicitada.

Nesse sentido, a ciência sempre assumiu uma tendência de compor transexuais e travestis como objetos de pesquisa, definindo suas existências por eles e elas. Geralmente no lugar de pessoas cisgêneras, que nunca precisaram se afirmar enquanto cis, têm sua existência assegurada e legitimidade para teorizar acerca das demais; na contramão, os corpos que carregam o rótulo de trans costumam ser postos à dúvida a todo o tempo.

É nessa via que nomear a cisgeneridade é uma estratégia política de identificar esse lugar que define tudo, menos a si mesmo, o lugar que origina o entendimento de mundo ao se colocar como referência.

Não existe um material de exames ou testes que validem o diagnóstico de TIG, sendo o único referencial a convenção de papéis masculinos ou femininos. Esse é um caminho diagnóstico extremamente frágil, falho, ancorado no binarismo social de comportamentos e que descarta a subjetividade. As psicólogas Sampaio e Coelho (2013) fazem críticas contundentes inclusive ao protocolo de atendimento nos serviços de saúde que, muitas vezes, ao invés de preparar a pessoa para o processo transexualizador, os acompanhamentos psicológico e psiquiátrico assumem função seletiva e rastreadora de disfunções.

No que concerne à saúde de pessoas trans no Brasil, a Medicina foi a primeira categoria profissional a se posicionar. A título de curiosidade, esse processo só se iniciou por conta da cassação do médico Roberto Farina que, na década de 1970, polemizou os ideais da época ao realizar a primeira cirurgia de redesignação sexual em uma mulher transexual, Waldirene. Após acusações de infração ética e um período deveras conturbado, o Conselho Federal de Medicina (CFM) passou a reconhecer a relevância cirúrgica sem atribuir a crime ou mera estética.

A Resolução do CFM, publicada em 1997 e identificada por $n^{\circ} 1.482 / 97$, versava acerca das cirurgias de redesignação sexual e modificações corporais. Nesse momento, se atestou a descriminalização das transformações corporais e definiu pessoas trans enquanto "portador de desvio psicológico permanente de identidade sexual, com rejeição do fenotipo e tendência à auto mutilação e ou auto-extermínio" (CFM, 1997, p. 1).

O que se observa fortemente é a perspectiva de adequação genital ao psiquismo, marcando o des- 
conforto e a necessidade de mudança no corpo como características centrais da experiência trans. A Resolução sofreu duas alterações, em 2002 e a atualmente em voga $\mathrm{n}^{\circ} 1955$ (2010), sendo mais criteriosa nos aspectos éticos e técnicos, avançando para caracteres secundários, ampliando os procedimentos para hospitais públicos e privados, e destacando a liberdade de escolha do indivíduo sem discriminação. Todavia, pode-se perceber a relação estrita de ajustar o sexo ao gênero, ainda sem grande superação dos preceitos cisheteronormativos.

É comum a inclinação para o detalhamento do perfil da verdadeira transexualidade. Entretanto, conceber a existência de original e cópia quando se fala de gênero é um retorno ao essencialismo, à ideia de normal e patológico, do legítimo e do ilegítimo. Essa conduta é conivente com o silenciamento de pessoas trans, contraria a saúde mental e a escuta de suas narrativas pela via direta ao invés do olhar do outro.

Pelo apanhado demonstrado até aqui, identifica-se nas palavras de Berenice Bento um trânsito entre "identidades pervertidas, transtornadas, disfóricas e psicóticas" (Bento, 2014, p. 53). O caminho da pluralidade da existência humana se fragiliza na perspectiva anterior, inclusive na forma de experienciar a transgeneridade. Como meio de existir e resistir, os estudos transviados emergem, assim, com novos paradigmas:

Nos estudos transviados os discursos médicos passam a ser analisados como engrenagens discursivas que limitam a existência da diversidade dos desejos, dos gêneros, das sexualidades ao âmbito das estruturas fixas corpóreas. E assim se estabelece uma disputa epistemológica onde o corpo passa a ser um significante com múltiplos significados, uma estrutura estruturante em permanente processo de transformação (Bento, 2014, p. 49).

A partir de narrativas imersas na representatividade, as pautas de pessoas trans se ampliam para além dos diagnósticos, abarcando lutas como: despatologização e rompimento com os manuais diagnósticos; retificação dos documentos pessoais; retirada da intersexualidade do enquadramento binário compulsório; combate à transfobia via direitos cidadãos - trabalho, saúde, segurança e educação (Sampaio, \& Coelho, 2013).

\section{Os saberes subversivos emergem}

Em termos de mudanças sociopolíticas e intelectuais, certamente deve-se mencionar a emergência dos movimentos sociais nas décadas de 1960-1970. É esse o mesmo período de efervescência da era da conceituação feminista acerca de gênero e das diferenças sexuais. Se solidificam os núcleos de estudos, mídias, organizações de cunho feminista e, com isso, se enfatizam os furos nos setores de saberes científicos.

O processo de apagamento histórico das existências trans, alinhadas ao sexismo, omitiu proposital e violentamente até a tomada de força dos movimentos sociais, como o feminismo que tornou pública a discussão acerca da desnaturalização do corpo e papeis sociais (Rodovalho, 2017).

Uma vez que se entende o processo como natural e binário do sexo-gênero, as identidades trans representam um conflito estrutural para as normas de gênero. $\mathrm{O}$ desequilíbrio no que se entende enquanto imutável, lei absoluta do funcionamento humano, reflete no desrespeito, tentativa de controle e patologização desses corpos.

A naturalização de diferenças sexuais e determinação da existência pela via biológica é posta em questão pelos saberes subversivos como nunca feito pela ciência hegemônica, considerando o corpo como uma esfera política e complexa.

A concorrência da cultura com a natureza, gênero e corpo, se desmistifica ao referir que é impossível segregar as duas vertentes ao tempo que uma se molda em relação à outra, é um processo simultâneo e inseparável.

Apesar de não enfatizar o caso da transexualidade em seus escritos, a francesa e feminista lésbica, Wittig (2006) aborda considerações caras acerca de gênero e sexualidades. Delimita como alvo o pensamento hétero que, por sua vez, retira a autenticidade de qualquer tipo de diferença da noção do ser humano padrão, por isso atinge altos níveis de impacto nas vivências. É um poder abstrato que age materialmente por meio da opressão.

A dissolução desse sistema do pensamento hétero, segundo Wittig, está na união dos signos de diferença entre homens e mulheres (seguindo a lógica semelhante da luta de classes); fazendo emergir os discursos desviantes. Diferença, para a autora, é um conceito chave manipulado em prol da regulação da desigualdade. 
Falando em proporções internacionais, certamente a filósofa Judith Butler pode ser considerada uma das principais referências acerca desta discussão. A obra lançada em 1990, Problemas de gênero, ajuda a inaugurar novas abordagens na produção do saber que funde gênero e sexualidade.

O uso da palavra problema não tem intenção de ser negativista, apenas incitar o debate que esquematize meios para lidar com a questão das diferentes conceituações de gênero, no sentido de que algumas permeiam bases heterossexuais e hierárquicas. Butler refere que “[...] rir de categorias sérias é indispensável para o feminismo. Sem dúvida, o feminismo continua a exigir formas próprias de seriedade" (2003, p. 9).

Sob uma perspectiva pós-estruturalista, alinhada com os estudos queer, o livro objetiva, dito no fim do prefácio, superar estruturas fixas acerca de gênero e a acomodação científica, entendendo a necessidade da colaboração de diversas áreas para a construção do conceito.

Ela vai trabalhar com o conceito foulcaultiano de poder por três instâncias: sexo, gênero e desejo. $O$ caminho é traçado pela genealogia, a qual não promete respostas sobre raízes, e sim compreender os efeitos do falocentrismo e heterossexualidade compulsória nos corpos através das relações. Esses sistemas são vistos como instituições, discursos e práticas.

A famosa (des) construção de sexo e gênero é discutida aqui. Rememorando o conceito popular de gênero como as interpretações culturais do sexo biológico, Butler faz questionamentos que levam a novas direções teóricas. A tese é de que é o discurso hegemônico que molda o sexo como incontestavelmente anatômico e binário. E é exatamente essa convicção que mantém estável o sexo pré-discursivo binário.

O sexo sempre foi posto na esfera natural, atribuindo ao gênero toda a formação das consequências culturais. Butler vai discordar dessa abordagem ao perceber o sexo também como imerso em uma percepção cultural, situado historicamente e produzido pelo discurso científico como essencialmente biológico. Aqui se encaixa sua célebre, e polêmica, frase: "talvez o sexo sempre tenha sido gênero, de tal forma que a distinção entre sexo e gênero revela-se absolutamente nula" (Butler, 2003, p. 27).

Seguindo uma linha também do pós-estruturalismo, a acadêmica italiana, Lauretis (1994) reflete sobre o emprego dos conceitos de gênero meramente como diferença sexual. O que ela reflete é que pensar em diferença sexual continua estabelecendo o viés binário marcado pela biologia e, além disso, reitera o homem (cisgênero) no lugar de referencial para, então, identificar na mulher o diferente.

Essa análise é uma lembrança cuidadosa acerca da reafirmação de posições desiguais que privilegiam o homem como ponto de partida para o desenvolvimento de teorias, o que gera duas discussões: o pensamento patriarcal pode ser nocivo inclusive para os saberes subversivos por conta da sua abrangente impregnação sistemática; a ideia da mulher como o ser diferente do homem é um impedimento de esmiuçar as diferenças dos papéis sexuais para a além da ideia universal que consta a análise dos dois sexos (Lauretis, 1994).

Para a autora, a solução seria articular gênero não como sinônimo de diferença sexual ou imbricação, mas como esferas que se relacionam como produto, derivação, efeito. O título do texto aqui referenciado, A tecnologia do gênero, faz alusão ao termo de Foucault, tecnologia sexual, pois, Lauretis (1994) enxerga o gênero também como oriundo de variadas tecnologias sociais cotidianas e institucionalizadas. Enfatiza também que não se trata de algo inerente, que já vem marcado no corpo pelas diferenças sexuais, mas que se produzem.

Gênero, portanto, diz respeito a relações, não pode ser pensado individualmente. O indivíduo é inserido na relação por meio de sua classificação, classe, com um indivíduo de outra classe. A percepção das diferenças é retratada em desigualdades, hierarquias, e em processos compulsórios de dominados e dominadores que são combatidos pela contracultura.

Em contexto brasileiro, há inúmeras pesquisas em prol da diversidade sexual. Entretanto, assim como a maior parte da América Latina, a tradição LGBTfóbica é extremamente carregada e danosa. Tendo grande influência do cristianismo e do patriarcado, o enaltecimento dos valores da família tradicional, entre outros, perpetua até hoje como atores da institucionalização da intolerância e disseminação da população LGBT como ameaça aos bons costumes.

As práticas homofóbicas no Brasil são subnotificadas e, muitas vezes, mascaradas por fazerem parte da cultura, o mesmo certamente acontece com a transfobia. Apesar do maior direcionamento para o combate das violências explícitas que ferem o corpo físico, é preciso marcar que as práticas 
entendidas como "sutis" são responsáveis por provocar grande nível de sofrimento psíquico em todas as faixas etárias.

Nascimento (2010) atenta para a banalização de práticas e discursos que acabam por consentir com a lógica de subalternização por terceiros ou que podem ser internalizadas pelo próprio indivíduo. Ou seja, a reprodução de violência está presente também em ocasiões definidas como pouco ou nada agressivas, como brincadeiras, piadas, expressões faciais, esquiva, que não tratam diretamente da discriminação.

Pensando no caráter relacional entre sujeito e sociedade, o gênero é fundamental na cultura ocidental como elemento organizador, o que rumina de certa forma na autodeterminação como dependente da inteligibilidade do coletivo. Nesse sentido, a "reivindicação última das pessoas trans é pelo reconhecimento social de sua condição humana" (Bento, 2014, p. 51).

Rodovalho (2017) elucida essa nuance abordando que a autoidentificação nem sempre é o bastante a respeito da identidade de gênero, visto que como sujeitos relacionais a vivência em harmonia consigo e com o outro, assim como a equiparação requer a colaboração de todas e todos, trans e cis.

Isto posto, os saberes subversivos são atribuídos a um projeto emancipatório que rompe completamente com as hierarquias do conhecimento, onde os saberes são vistos como situados, não universais e parciais. Dessa forma, a ciência universal, objetiva e neutra é contestada e abre margem para um agregado de perspectivas.

O transfeminismo faz parte da manifestação de vozes marginais. Emerge no Brasil nos anos 1980, baseado no feminismo negro, na interseccionalidade e no pós-estruturalismo. As pautas reivindicam lutas no cenário da militância e dos paradigmas da ciência, simultaneamente, como o lugar de fala, as narrativas, o protagonismo de saberes sobre si, rompimento com a objetificação (Matto,s \& Cidade, 2016).

As transfeministas apontam a função regulatória da cisnormatividade e suas consequências nocivas. Criticam a forma que o conhecimento sobre pessoas trans é produzido a partir da objetificação e fetichização, como discutido anteriormente. "Ativistas e pesquisadoras transfeministas têm apontado esse ponto cego na produção do conhecimento das ciências humanas e de saúde" (Mattos, \& Cidade, 2016, p. 134).
As autoras referenciadas, e psicólogas, acreditam que a interlocução com o transfeminismo é fundamental para transformar paradigmas, se comprometer com a ética, a política e romper com a cisgeneridade compulsória inerente ao positivismo. Também é uma crítica da tendência essencialista de alguns feminismos, que contribui para um direcionamento segregado do que se entende por mulher (Mattos, \& Cidade, 2016).

Outro movimento, iniciado na Espanha desde 2009, é a Rede Internacional pela Despatologização Trans, do inglês Stop Trans Pathologization - STP, que se articulou no intuito de reclamar direitos fundamentais segundo a autodeterminação grupal. Abrangendo a população trans e intersex, em 2015 a STP já constava de 397 coletivos pelo mundo em mais de 45 cidades (Stop Trans Pathologization [STP], 2012).

A página oficial da Rede consta de sete pautas principais: erradicação classificatória enquanto doença; retificação dos documentos sem aval médico/psicológico; poder decidir livremente acerca de procedimentos corporais sem acompanhamento compulsório; veto às cirurgias prematuras em pessoas intersex; acesso digno ao mercado de trabalho, segurança e saúde; políticas de acolhimento às pessoas trans imigrantes; reconhecimento institucional, combate e notificação dos efeitos da transfobia.

Concomitante às ocasiões de subalternização, é importante mencionar que a resistência sempre esteve montada. Pode-se referir como alusão a momentos históricos de resistência e conquistas, o memorável ato de Stonewall em 1969; a articulação do movimento LGBT pelo direito de expressão no ambiente público; a Parada do Orgulho LGBT que reuniu 3 milhões de pessoas em 2018 em São Paulo, sem contar as demais edições.

No âmbito da saúde, 2018 proporcionou a mais recente mudança diagnóstica da transexualidade na CID-11, que entrará em vigor em 2022. Para a transfeminista,Bagagli (2018), a transferência para a categoria de condições relacionadas à saúde sexual é uma conquista importante, mesmo que com controvérsias, para assegurar a assistência a pessoas trans sem o viés patológico.

\section{A pauta trans na Psicologia hoje}

Muito se fala atualmente de pessoas trans, mas a mesma ênfase e peso de nomenclatura não se emprega às pessoas cis (Rodovalho, 2017). 
Enquanto as pessoas trans sofrem de apagamento na sociedade, as mesmas sempre existiram para a Psicologia, Psiquiatria e Medicina nos consultórios e manicômios onde a loucura era a única via, mas pouco se falava da parcela social e cultural nos mecanismos de adoecimento.

Adentrando no espaço discursivo psicológico iniciado no século XX,,Wittig (2006) faz duras críticas à ideia da psique humana descolada da historicidade, descontextualizada das intersecções e trabalhada como modo de funcionamento universal. Ideia essa, como o inconsciente, é proferida por intermédio das teorias e da terapia; ela exibe a importância do poder da linguagem como método em que a/o profissional é a pessoa autorizada a interpretar os signos, ou moldá-los.

As críticas ao acompanhamento psicológico continuam, a autora se baseia na psicanálise, mas pode-se expandir a ideia para demais abordagens. Acredita que o oferecimento da escuta psicanalítica decente só será possível ao passo que incorpore uma perspectiva política, já que consta de uma leitura de sujeitos apoiada na norma heterossexual. Realça que os conceitos psicanalíticos se utilizam de mitos e metáforas de cunho altamente heterossexual para difundir sua teoria e isso repercute nos encaminhamentos terapêuticos (Wittig, 2006).

Mattos e Cidade (2016) referem que determinadas tendências não ficaram completamente no passado. Não raro a prática e ciência psicológica prossegue atestando interesses normativos, colaborando para sua perpetuação nos aparelhos do Estado, a exemplo da perspectiva empregada em muitos laudos destinados a pessoas trans.

A discussão sobre a transexualidade tem encarado pontos a comemorar ao mesmo tempo que sofre retaliações. Se antes os (as) trans não tinham a menor visibilidade, eram fadados a viver no silêncio; hoje a transexualidade é um assunto em alta e, por ser de conhecimento público, sofre ataques diretos de diversos setores.

Após muitas reivindicações e atuações militantes nos órgãos deliberativos, os últimos anos trouxeram conquistas inestimáveis, por exemplo: ambulatórios cirúrgicos e garantia do uso do nome social no Sistema Único de Saúde (SUS); luta articulada internacionalmente; retirada da categoria de transtornos mentais do CID; cotas em programas de mestrado e doutorado de universidades públicas; retificação de nome no registro civil sem necessidade de laudo psicológico.

Em toda essa conjuntura, é impreterível se discutir o campo da saúde mental, que não raro adota postura de identificar pessoas trans como incapazes de decidir sobre si mesmas, em que a retirada da autonomia não apresenta justificativas plausíveis senão o entendimento arbitrário de doença.

Desconsiderando que, ao se tratar de posições masculinas ou femininas requer, obrigatoriamente, um olhar interdisciplinar que ultrapassa o saber exclusivamente biologicista, ou de aptidão médica, sobre a anatomia e binarismo sexual (Sampaio, \& Coelho, 2013).

O estabelecimento da anormalidade é anterior à aproximação do indivíduo transexual, que deve provar sua sanidade nesse caminho invertido pela lógica da área da saúde. O convencimento também passa pela equipe que, por intermédio de um laudo com CID, permite acesso ao serviço transexualizador. Esse é mais um fator de dilema, enquanto a retirada dos manuais é uma exigência, pode ser utilizada pelo Estado para se isentar da oferta de serviços especializados.

No âmbito da saúde pública, o Ministério da Saúde implementou a Portaria relativa ao Processo Transexualizador em 2008, desde então a Psicologia fica entendida pelo SUS e pelo CFM como parte importante no atendimento e cuidado de pessoas trans, integrando a equipe do Processo Transexualizador.

Concomitante a esse movimento, a partir de 2011 e 2012 o CFP começa a se mobilizar em prol de regulamentar e orientar a referida prática. As primeiras considerações e orientações constam de 2013, na Nota técnica sobre processo transexualizador e demais formas de assistência às pessoas trans (Conselho Federal de Psicologia [CFP], 2013).

A nota técnica se divide em cinco considerações e oito orientações para a categoria. As considerações enfatizam a despatologização, assim como o respeito e garantia de acompanhamento de qualidade, outro ponto a se destacar é que o atendimento não se restringe a casos de mudanças corporais, e sim às demandas psicossociais do sujeito.

As orientações dialogam com as premissas apresentadas acima, e importam muito no sentido da posição que profissionais de Psicologia devem adotar no seu trabalho com pessoas transexuais e travestis. Se reitera o rompimento patologizante, o 
incentivo da autonomia, projeto terapêutico singular e flexível, responsabilidade com sua prática durante todo o processo.

Destaca-se para essa discussão a $5^{\mathrm{a}}$ orientação: “A(o) psicóloga(o) deverá valer-se de pesquisas e estudos culturais na área de gênero e sexualidade na tentativa de buscar um respaldo teórico para entendimento desse contexto social para superação da heteronormatividade" (CFP, 2013, p.3).

A Psicologia brasileira se coloca deliberadamente a favor das diversidades, tendo dois marcos no que concerne à orientação sexual e identidade de gênero: a Resolução no 01/1999 e a Resolução no 01 (2018). Desde 2011 (Sousa, \& Cavalcanti, 2016), ações a favor da despatologização das identidades trans fazem parte da agenda do CFP através da Comissão de Direitos Humanos.

Vale a pena comentar brevemente a Resolução ${ }^{\circ}$ 01/1999 a título de diferenciar seu propósito, embora também seja caro à profissão. Lançada em março de 1999, a mesma se refere à atuação de psicólogas/os no que concerne à sexualidade, sobretudo à orientação sexual. Essa Resolução também serviu como modelo internacional, inclusive para a Associação Americana de Psicologia (APA).

Nesse momento, se considera as questões ligadas à sexualidade como presentes nos mais variados contextos de atuação da Psicologia, mesmo que não seja de forma direta. Ademais, a homossexualidade é dissociada da ideia de doença, distúrbio e perversão. Desse modo, se estabelece o papel da Psicologia em combater discriminações, preconceitos e estigmas.

A mais recente, publicada em janeiro de 2018, dispõe sobre o atendimento às pessoas travestis e transexuais. Baseada na Constituição de 1988, na Declaração Universal dos Direitos Humanos, Política Nacional de Saúde Integral LGBT e demais referências a favor da diversidade e contra a patologização de identidades de gênero e orientação sexual.

A Resolução inova ao trazer terminologias atualizadas e que dialogam com o campo interdisciplinar dos estudos de gênero, assim como documentos oficiais de referência nacional e internacional. Conceitos como cisnormatividade, heteronormatividade, padrões ocidentais, autonomia e autodeterminação são colocados criticamente para a valorização das expressões de gênero, seja qual for. Esse direcionamento, por exemplo, não se encontra na Resolução nº 01/1999.
Através de nove artigos, o Conselho Federal de Psicologia explicita o papel da/o psicóloga/o em não corroborar para a transfobia, sendo agente ativo de transformação social. É importante frisar que não se trata apenas de não ser conivente na própria prática e de terceiros, mas de combater e se posicionar contra todo e qualquer evento transfóbico. Isso se destina a instituições, demais profissionais, pronunciamentos, recursos virtuais, técnicas, atitudes.

Com a Resolução no 1, (2018) a categoria profissional é orientada a acolher a autodeterminação das pessoas transexuais e travestis, e explicitamente se proíbe em qualquer hipótese terapias de reversão de identidade de gênero. O combate à transfobia é deslocado da luta individual para o dever do coletivo.

Em menos de um ano de vigência, a Resolução já recebeu dois processos, sendo o primeiro datado de três meses após a publicação. As tentativas de boicote se mostram incessantes sob alegação de ilegalidade e autoritarismo, mesmo com as vitórias judiciais. Não podemos esquecer que situação similar ocorre com a Resolução no 01/1999 sob a justificativa de ferir a autonomia profissional.

O "abrigo da transfobia" não deve se destinar apenas a quem condiz com a passabilidade. A identidade não é decidida por decreto. A autora explicita:

Ninguém tem culpa, ninguém escolhe. É necessário entender mais de aquisição da linguagem, de psicanálise, se quisermos compreender o que significa esse "sentir-se mulher" que mulheres trans alegam, esse "sentir-se homem" que homens trans alegam. Isso é o que sabem dizer, as palavras que temos à disposição, que nos ensinaram. É necessário saber ler para além da superfície dessas palavras (Rodovalho, 2017, p. 371).

É preciso romper com a perspectiva de pânico moral e julgamento de valor sobre a sexualidade e gênero. Acolher as demandas da população trans para além da associação compulsória à IST, HIV/AIDS, ou a laudos para modificações corporais. Praticar não só ouvir, mas escutar (são processos simbolicamente distintos) o que elas têm a dizer.

\section{Considerações finais}

Através do texto pode-se notar que as ciências psis acompanham a esfera da identidade de gênero, 
assim como da sexualidade humana, desde o princípio das aproximações teóricas do tema. Também se viu que as definições não permaneceram as mesmas ao longo do tempo, o que exclui o caráter imutável do discurso científico. Além disso, é possível indicar que as alterações diagnósticas e teóricas são tanto fruto dos avanços da ciência quanto das cobranças maciças em nível social.

Ademais, é preciso conceber que os saberes psicológicos se estendem à vida cotidiana das pessoas, visto que se trata de um campo que incide diretamente nos comportamentos, pensamentos e costumes. É um mecanismo de referência para as relações humanas, para pleitear ações e normativas políticas, formas de cuidado institucionais, educação das crianças e adolescentes.

O efeito da Psicologia deve ser encarado com muita seriedade, visto que os registros históricos da formação da profissão relembram momentos taxativos em termos de direcionamento de controle e normatização de condutas legitimados via práticas psicológicas.

Não é à toa que diversas tentativas de ataques ao posicionamento a favor da diversidade sexual e de gênero são reiteradas, a exemplo da ação recente movida em prol da derrubada da Resolução no 01/99. Apesar da célebre decisão do Supremo Tribunal Federal em manter a Resolução intacta, cabe problematizar a falta de consenso de psicólogas/os a respeito de terapias para reversão sexual, visto que a mentoria da derrubada foi requisitada por grupos da própria categoria.

A questão não se refere a defender o imperativo primordial da biologia ou da cultura sobre o sujeito e sua socialização, de forma que a influência de uma anularia a importância da outra. Todavia, considerar a existência dessa disputa é importante para analisar as repercussões no tratamento, na promoção de saúde mental, principalmente porque os atributos biologizantes têm dominado o status de veracidade na leitura dos corpos.

Butler faz uma crítica justamente ao apego a uma perspectiva única, abordando que ao eliminar a compulsão da biologia, corre-se o risco de a cultura entrar nesse lugar. Sendo entendido o corpo sexuado como mero receptor das leis externas e sujeito sem protagonismo, acaba por trazer outros tipos de problemas. Por isso propõe que o gênero consiste em categoria analítica, inscrito nos indivíduos e se evidencia nas relações que, por sua vez, são regidas pela linguagem (Butler, 2003).
É por essa via que concepções da Psicologia sobre a socialização podem apresentar riscos e servir de aporte para argumentos transfóbicos, no sentido de que algumas correntes enfatizam a diferença de socialização já na fase da infância como fundamental para desconfiar das identidades trans. Essa noção da socialização de gênero pode estar revestida de uma lógica científica que bebe da cisnormatividade, até por conta do fato de que pessoas trans geralmente estão no lugar de pacientes e não de profissionais.

Também é preciso discutir que o sofrimento psíquico é uma esfera pouco explorada no que se refere às identidades trans. Não raro é associado, com extremo simplismo, como oriundo da transgeneridade em si e suas consecutivas modificações corporais (Bagagli, 2018). Isso também significa que a questão é resumida à imagem corporal, padronizada, e é negligenciado o sofrimento psíquico que se manifesta por outros fatores. Por isso defende que:

É preciso que o sofrimento psíquico de uma pessoa seja reconhecido socialmente. É preciso que a voz de uma pessoa que sofre seja ouvida e que seu sofrimento ganhe inteligibilidade. Quando o sofrimento é compreendido (ou melhor: acolhido) intersubjetivamente, socialmente e institucionalmente a própria existência da pessoa que sofre ganha sentido. Dai essa pessoa vai poder existir para além das cercas limitantes do seu sofrimento (Bagagli, 2018, p. ).

A questão do sofrimento é muito delicada nesses casos, pois pode desonestamente ser utilizado como justificativa para critérios diagnósticos descontextualizados. É algo que pode acarretar, por exemplo, na ideia da transgeneridade legítima, ou na generalização do sofrimento psíquico que silencia as histórias singulares.

Outro ponto é fundamental é desenvolver a compreensão de que a experiência trans não necessariamente vem acompanhada de sofrimento ou demandas diferentes de outros grupos. Neste fluxo, salientar o investimento na saúde mental percorre uma outra possibilidade que não o foco exaustivo em manifestações patológicas do público atendido.

As psicólogas Mattos e Cidade fazem uma advertência sob essa ótica: "É urgente que, ao nos situarmos no campo da produção em psicologia, dialoguemos com esses diferentes lugares de fala, refazendo-nos desde nossas referências e matrizes epistêmicas até nossas práticas profissionais" (2016, p. 149). 
Não basta instituir normativas se os hábitos derivados do estigma continuam a se reproduzir, se não houver o interesse individual das/os profissionais e das categorias em se revisitar.

Ainda se trata de um campo incipiente, o qual indispensavelmente requer novas aprendizagens e refinamento na prática no contato com os desafios que vão emergindo das demandas que fogem do aparato já suportado pelo modelo hegemônico. Talvez o cerne inicial esteja entre a escolha de permanecer em lugares de conforto ou carregar a abertura para investir no vínculo e construção com o outro.

\section{Referências}

Bagagli, B. P. (2018). A retirada da transexualidade da classificação de doenças e o sofrimento psíquico. Recuperado de https://transfeminismo.com/a-retirada-da-transexualidade-da-classificacao-de-doencas-e-o-sofrimento-psiquico/

Bento, B. (2014). O que pode uma teoria? Estudos transviados e a despatologização das identidades trans. Florestan, 1(2), 46-66.

Butler, J. (2003). Problemas de gênero: Feminismo e subversão da identidade. Rio de Janeiro: Civilização Brasileira.

Conselho Federal de Psicologia - CFP. (2013). Nota técnica sobre processo transexualizador e demais formas de assistência às pessoas trans. Brasília, DF: o autor. Recuperado de https://site.cfp.org.br/wp-content/uploads/2013/09/ Nota-t\%C3\%A9cnica-processo-Trans.pdf

Harding, S. (2004). Introduction: Standpoint theory as a site of political, philosophic and scientific debate. In: Harding, S. (Ed.), The feminist standpoint theory reader: Intellectual and political controversies (pp.1-15). New York, NY: Routledge.

Lauretis, T. (1994). A tecnologia do gênero. In: Hollanda, H. (Org.), Tendências e impasses: O feminismo como crítica da cultura (pp. 206-242, S. Funck, trad.). Rio de Janeiro, RJ: Rocco.

Mattos, A. R., \& Cidade, M. L. R. (2016). Para pensar a cisheteronormatividade na psicologia: Lições tomadas do transfeminismo. Revista Periódicus, 1(5), 132-153. https://doi.org/10.9771/peri.vli5.17181

Nascimento, M. A. N. (2010). Homofobia e homofobia interiorizada: Produções subjetivas de controle heteronormativo?. Athenea Digital, (17), 227-239. https://doi.org/10.5565/rev/athenead/v0n17.652

Oakley, A. (2016). Sexo e gênero. Revista Feminismos, 4(1), 64-71.

Stop Trans Pathologization - STP. (2012). Manifesto: Rede Internacional pela Despatologização Trans. Disponível em: https://www.stp2012.info/old/pt/manifesto.

Resolução CFP No 1, de 22 de março de 1999. Estabelece normas de atuação para os psicólogos em relação à questão da Orientação Sexual. Recuperado de https://site.cfp.org.br/wp-content/uploads/1999/03/resolucao1999_1.pdf

Resolução No 1, de 29 de janeiro de 2018. Estabelece normas de atuação para as psicólogas e os psicólogos em relação às pessoas transexuais e travestis. Disponível em: https://site.cfp.org.br/wp-content/uploads/2018/01/ Resolu\%C3\%A7\%C3\%A3o-CFP-01-2018.pdf

Resolução CFM No 1.955, de 12 de agosto de 2010. Dispõe sobre a cirurgia de transgenitalismo e revoga a Resolução CFM no 1.652/02. Diáiro Oficial da União, 3 set. 2010.

Rodovalho, A. M. (2017). O cis pelo trans. Revista Estudos Feministas, 25(1), 365-373. https://doi.org/10.1590/ 1806-9584.2017v25n1p365

Sampaio, P. L. L., \& Coelho, D. A. T. M. (2013). A transexualidade na atualidade: Discurso científico, político e histórias de vida. Anais do Seminário Internacional Enlaçando Sexualidades, Salvador, BA, Brasil, 3.

Sousa, D., \& Cavalcanti, C. (2016). Entre normas e tutelas: Pensando (im) possibilidades da Psicologia em interface com transgeneridades. In A. Denega, D. S. V. Andrade, \& H. M. Santos (Orgs.), Gênero na psicologia: Saberes e práticas (pp. 126-139). Salvador: CRP-03,

Stoller, R. (1968). Sex and gender: The development of masculinity and femininity. London: Ed. Maresfield Library.

Wittig, M. (2006). El pensamiento heterosexual. In Wittig, M. El pensamiento heterosexualyotros ensayos (pp. 45-57). Madri: Egales. 


\section{Lara Araújo Roseira Cannone}

Mestranda no Programa de Pós-graduação em Estudos sobre a Mulher, Gênero e Feminismo da Universidade Federal da Bahia (PPGNEIM/UFBA), Salvador - BA. Brasil.

E-mail: laracannone@gmail.com

(iD) https://orcid.org/0000-0002-6047-1475

Endereço para envio de correspondência:

Rua Professor Aristides Novis, 197 - Federação. CEP: 40210-909, Salvador - BA.

Recebido 10/09/2019

Aceito 04/10/2019

Received 09/10/2019

Approved 10/04/2019

Recibido 10/09/2019

Aceptado 04/10/2019

Como citar: Cannone, L. (2019).Historicizando a Transexualidade em Direção a uma Psicologia Comprometida. Psicologia: Ciência e Profissão. 39(n.spe 3), 21-34. https://doi.org/10.1590/1982-3703003228487

How to cite: Cannone, L. (2019). Historicizing Transsexuality toward a Committed Psychology. Psicologia: Ciência e Profissão. 39(n.spe 3), 21-34. https://doi.org/10.1590/1982-3703003228487

Cómo citar: Cannone, L. (2019). Historizando la Transexualidad Hacia una Psicología Comprometida. Psicologia: Ciência e Profissão. 39(n.spe 3), 21-34. https://doi.org/10.1590/1982-3703003228487 